\title{
POSSIBILIDADES E LIMITES DO TRABALHO INCLUSIVO NA EDUCAÇÃO PROFISSIONAL E TECNOLÓGICA
}

\section{Possibilities and Limits of Inclusive Work in Professional and Technological Education}

\author{
Wanessa Moreira de Oliveira ${ }^{*}$ \\ Ediclea Mascarenhas Fernandes**
}

\begin{abstract}
Resumo: O presente estudo trata da temática da educação especial e inclusiva no âmbito da educação profissional e tecnológica, a partir de uma pesquisa de campo realizada no Instituto Federal de Educação, Ciência e Tecnologia do Sudeste de Minas Gerais. Esse artigo parte de um estudo maior, que resultou em uma dissertação de mestrado, e objetiva apreender a realidade institucional do Instituto Federal (IF) pesquisado e promover reflexão sobre o processo de inclusão e atendimento aos discentes público-alvo da educação especial. O estudo ampara-se na metodologia de pesquisa qualitativa, sendo utilizadas, como instrumentos de coleta de dados, a entrevista semiestruturada e a análise documental. Para tratamento dos dados coletados, foi utilizada a análise de conteúdo de Bardin. O trabalho de campo constituiu-se através da realização de entrevistas com coordenadores dos Núcleos de Atendimento às Pessoas com Necessidades Específicas (NAPNEs) existentes na instituição, com a finalidade de compreender a realidade institucional. As análises empreendidas nesta pesquisa possibilitaram a identificação de fragilidades e potencialidades da instituição para o exercício da educação inclusiva. Uma das principais limitações identificadas foi a ausência de uma política específica para direcionar e organizar as práticas de inclusão, dificultando o estabelecimento de uma cultura inclusiva no IF. Todavia, foi possível observar que o papel social da instituição, de zelar pela equidade e pelo exercício da cidadania, assim como a existência de alguns NAPNEs como referência de apoio para a educação especial no ensino regular revelaram-se potenciais para o exercício educacional pelo viés inclusivo.
\end{abstract}

Palavras-chave: Educação Profissional e Tecnológica. Educação Inclusiva. Políticas de Inclusão.

Abstract: The present study deals with the theme of special and inclusive education in the scope of professional and technological education, based on a field research carried out at the Federal Institute of Education, Science and Technology of the Southeast of Minas Gerais. This article is part of a larger study that resulted in a master's thesis, and aims to apprehend the

\footnotetext{
* Assistente Social; Mestra em Diversidade e Inclusão pela Universidade Federal Fluminense; Doutoranda do Programa de Pós-graduação em Ensino em Biociências e Saúde do Instituto Oswaldo Cruz/FIOCRUZ. Servidora do IF Sudeste MG. https://orcid.org/0000-0002-8679-3296.E-mail: oliverwanessa85@gmail.com

** Psicóloga; Pedagoga; Mestra em Educação pela Universidade do Estado do Rio de Janeiro; Doutora em Ciências na Área de Saúde da Criança e da Mulher pela FIOCRUZ. Professora Adjunta da Universidade do Estado do Rio de Janeiro e Professora Permanente do Mestrado em Diversidade e Inclusão da Universidade Federal Fluminense. https://orcid.org/0000-0003-3998-2016 E-mail: professoraediclea.uerj@gmail.com
} 
institutional reality of the researched Federal Institute (FI) and promote reflection on the inclusion process and attendance to students target audience of special education. The study is based on the qualitative research methodology, using semi-structured interviews and document analysis as data collection instruments. Bardin's content analysis was used to treat the collected data. The fieldwork consisted of conducting interviews with coordinators of the Service Centers for People with Specific Needs (NAPNEs) existing in the institution, in order to understand the institutional reality. The analyzes undertaken in this study made it possible to identify the institution's weaknesses and potential for the exercise of inclusive education. One of the main limitations identified was the absence of a specific policy to direct and organize inclusion practices, making it difficult to establish an inclusive culture in the FI. However, it was possible to observe that the social role of the institution to ensure equity and the exercise of citizenship, as well as the existence of some NAPNEs as a reference for the support special education in regular education proved to be potential for educational exercise through inclusive bias.

Keywords: Professional and Technological Education. Inclusive education. Inclusion Policies.

\title{
1 Introdução
}

Em 2000, seguindo a perspectiva da inclusão, iniciada na década de 90 com a Declaração de Jomtien (UNESCO, 1990) e a Declaração de Salamanca (UNESCO, 1994), foi formatado, junto à Secretaria de Educação Profissional e Tecnológica do Ministério da Educação (SETEC/MEC), o Programa Educação, Tecnologia e Profissionalização para Pessoas com Necessidades Específicas (Programa TEC NEP), no intuito de instrumentalizar a Rede de Educação Profissional, Científica e Tecnológica (EPCT) para o desenvolvimento da educação inclusiva.

\begin{abstract}
A Ação TEC NEP visa expandir a Educação Profissional para a população com deficiência, buscando tornar seus beneficiários aptos tecnologicamente e ampliar seus conhecimentos e habilidades, como base para uma efetiva emancipação econômica e social. Este programa tem como propósito iniciar o processo de transformação da realidade atual. Além de ser uma questão de efetivação de direitos humanos e de direitos de cidadania das pessoas com necessidades especiais à Educação Profissional e ao Trabalho - a sua principal justificativa -, no médio e longo prazo, representará menos dispêndio com programas assistenciais, motivados, com razão, pela histórica exclusão social desse segmento da população (BRASIL ${ }^{1}, 2010$ apud NUNES, 2012, p. 25).
\end{abstract}

Uma das estratégias do Programa era a constituição dos Núcleos de Atendimento às Pessoas com Necessidades Específicas (NAPNEs) em todas as instituições da Rede EPCT, para que atuassem diretamente na implementação do Programa TEC NEP, intervindo, internamente, no atendimento às necessidades dos estudantes público-alvo da educação especial e no apoio ao desenvolvimento de estratégias pedagógicas e, externamente, no estabelecimento de parcerias com instituições que apoiam a educação de pessoas com deficiência (ANJOS, 2006).

\footnotetext{
${ }^{1}$ BRASIL. Ministérios da Educação. Documento base da Ação TEC NEP - Tecnologia, Educação, Cidadania e Profissionalização para pessoas com necessidades específicas. Versão III. Brasília, 2010 (texto digitado).
} 
Assim, os NAPNEs foram pensados para atuarem com papel principal no processo de inclusão, sendo constituídos por um(a) coordenador(a), designado por portaria institucional, e por um corpo de apoio, composto por servidores especializados, como psicólogos e sociólogos, além de outros servidores (técnicos e docentes), alunos e seus pais (NASCIMENTO e FARIA, 2013).

Os NAPNEs tinham como "objetivo principal criar, na instituição, a cultura da educação para a convivência, aceitação da diversidade e, principalmente, buscar a quebra de barreiras arquitetônicas, educacionais e atitudinais" (BRASIL 2, 2000 apud ANJOS, 2006, p. 40).

Esse Programa, segundo Nascimento e Faria (2013), contou com três momentos: de 2000 a 2003, foi o momento de sensibilização, com o intuito de apresentar o Programa às Instituições da Rede EPCT; de 2003 a 2006, foi o momento de consolidação do Programa, com a formatação dos grupos gestores e implantação dos NAPNEs nas instituições da Rede; e de 2007 a 2009, houve investimento na formação de recursos humanos e no uso e desenvolvimento de tecnologia assistiva.

Segundo Nascimento e Faria (2013), um quarto momento seria de instrumentalização dos NAPNEs, com aquisição de recursos multifuncionais e capacitação de pessoal, o que não foi possível, já que o Programa não teve continuidade após a extinção da Coordenação de Ações Inclusivas pela SETEC, em 2011.

Dessa forma, com o fim do Programa TEC NEP, muitas instituições da Rede EPCT, que ainda estavam em processo de expansão e consolidação, como algumas se encontram até os dias atuais, nem chegaram a implementar os Núcleos ou implementaram, mas não conseguiram sustentar a proposta do Programa sem o suporte dos grupos gestores e de recursos específicos.

A partir disso, outra Secretaria passou a responsabilizar-se pela política de inclusão educacional da Rede EPCT: a Secretaria de Educação Continuada, Alfabetização, Diversidade e Inclusão (SECADI).

Em 2013, a SECADI, em parceria com a Secretaria de Educação Superior (SESu), lançou um documento orientador sobre o Programa Incluir, que objetivava orientar as políticas de acessibilidade das Instituições Federais de Educação Superior (IFES), não contemplando as instituições que compõem a Rede EPCT (BRASIL, 2013).

O Programa em questão contemplava projetos de acessibilidade de Universidades Federais e Institutos Federais de Educação, Ciência e Tecnologia (IFs), desde 2005, através da concorrência por chamadas públicas. Mas, a partir de 2012, passou a fazer aportes específicos de recursos disponibilizados diretamente nas matrizes orçamentárias das Universidades Federais somente para a execução de ações de acessibilidade no âmbito do eixo "Acesso à Educação" do Plano Nacional dos Direitos das Pessoas com Deficiência - Viver sem Limite (BRASIL, 2013).

Interessante notar que, além do investimento no desenvolvimento da educação inclusiva em nível superior, com foco nas universidades, existiu, ainda, a aplicação de recursos públicos para a realização de ações de acessibilidade e inclusão nas escolas de educação básica, municipais e estaduais, novamente excluindo a educação profissional e tecnológica e, consequentemente, os IFs, responsáveis, também, pela educação básica.

Tal constatação fica evidente quando se observam os diversos programas de apoio e incentivo do governo federal ao desenvolvimento de práticas inclusivas para acesso e

\footnotetext{
2 BRASIL. Ministério da Educação. Programa TEC NEP - Educação, Tecnologia e Profissionalização para pessoas com necessidades educativas especiais. Brasília, 2000.
} 
permanência de estudantes público-alvo da educação especial nas escolas, como o Programa de Implantação das Salas de Recursos Multifuncionais, Programa Escola Acessível, Programa Transporte Escolar Acessível, Programa de Formação Continuada de Professores na Educação Especial, entre outros (MEC, 2014).

Assim, talvez por falta de ação ou de reconhecimento da importância dos investimentos por parte da SETEC/MEC, ou mesmo por falta de identificação da necessidade por parte dos gestores da Rede EPCT, os IFs ficaram desprovidos de recursos específicos para o desenvolvimento de ações de acessibilidade e inclusão.

Nessa perspectiva, em 2013, a SECADI expediu a Nota Técnica no 106 sobre Orientação à Implementação da Política Institucional de Acessibilidade na Rede EPCT, destacando a autonomia dessas instituições no desenvolvimento de uma política de acessibilidade e deixando clara a inexistência de um direcionamento de âmbito governamental e de um financiamento específico para tais ações.

\begin{abstract}
O financiamento das condições de acessibilidade deve integrar os custos gerais com o desenvolvimento do ensino, pesquisa e extensão das Instituições da Rede Federal de Educação Profissional, Científica e Tecnológica que devem procurar estabelecer uma política de acessibilidade voltada à inclusão das pessoas com deficiência, contemplando a acessibilidade no Plano de Desenvolvimento da Institucional - PDI; no planejamento e execução orçamentária; no planejamento e composição do quadro de profissionais; nos projetos pedagógicos dos cursos; nas condições de infraestrutura arquitetônica; nos serviços de atendimento ao público; no sítio eletrônico e demais publicações; no acervo pedagógico e cultural; e na disponibilização de materiais pedagógicos e recursos acessíveis (BRASIL, 2013a, p. 9).
\end{abstract}

Desde então, cabe a cada instituição da Rede EPCT responsabilizar-se pelo planejamento, financiamento, implementação e gestão de uma política institucional para educação inclusiva, de forma que considere as garantias estabelecidas pela legislação vigente e a ausência de um programa específico de apoio e investimento.

Nesse sentido, o presente artigo, que constitui um recorte do processo investigativo desenvolvido em um trabalho dissertativo de mestrado ${ }^{3}$, tem como objetivo identificar as potencialidades e limitações do processo de inclusão e atendimento aos discentes público-alvo da educação especial no IF Sudeste MG.

O esforço empreendido neste estudo qualifica-se, então, pela importância a qual ele representa na identificação das dificuldades institucionais para atendimento às demandas dos discentes público-alvo da educação especial e no delineamento de possibilidades para a construção de uma política inclusiva na educação profissional e tecnológica.

\title{
2 Metodologia
}

A realização da presente pesquisa está ancorada na metodologia de pesquisa qualitativa, tendo em vista que o objetivo proposto envolve a compreensão e o compartilhamento de saberes

\footnotetext{
${ }^{3}$ OLIVEIRA, Wanessa Moreira. Ações Inclusivas no Âmbito do IF Sudeste MG: um processo em construção. Niterói-RJ, 2017, 188f. Dissertação (Mestrado em Diversidade e Inclusão) - Programa de Pós-graduação em Diversidade e Inclusão, da Universidade Federal Fluminense. Niterói-RJ, 2017.
} 
e práticas de uma dada realidade social, uma realidade particular e específica, que, dificilmente, poderia traduzir-se em indicadores numéricos (MINAYO, 2015). de 2017.

O trabalho de campo ${ }^{4}$ foi realizado no ano de 2016, e o estudo, concluído em meados

\subsection{O local da pesquisa}

O IF Sudeste MG, locus do presente estudo, foi criado pela Lei ${ }^{\circ} .11 .892$, de 29 de dezembro de 2008, que instituiu a Rede EPCT e criou outros trinta e sete Institutos Federais de Educação, Ciência e Tecnologia. Ele foi concebido mediante integração entre um Centro Federal de Educação Tecnológica (CEFET), uma Escola Agrotécnica e uma Escola Técnica vinculada a uma Universidade Federal (BRASIL, 2014).

A instituição possui aproximadamente 17 mil discentes (dados de 2016), matriculados nas mais diversas modalidades de ensino, tanto presenciais quanto a distância, e distribuídos em dez campi, localizados nas regiões da Zona da Mata Mineira e Campo das Vertentes. Dentre o total de alunos, há registro de aproximadamente vinte identificados como público-alvo da educação especial. No entanto, acredita-se que esse número não representa a realidade, tendo em vista que a instituição não possui um sistema organizado de tais informações, assim como a Rede EPCT não possui um censo próprio que contemple tais especificidades dos estudantes (BRASIL, 2016).

\subsection{Os participantes}

De acordo com o objetivo traçado para a pesquisa, buscou-se privilegiar, como participantes do estudo, aqueles que tivessem uma atuação relacionada com o suporte de educação especial dentro de cada campus do IF investigado, com o intuito de que houvesse uma contribuição, a partir de suas experiências e das condições de seus campi, para com as reflexões almejadas.

Assim, conforme apresentado no Quadro 1, foram convidados a participar da pesquisa os coordenadores dos três únicos NAPNEs existentes e atuantes de três campi do IF Sudeste MG, a saber, Campus Juiz de Fora, Campus Rio Pomba e Campus Barbacena.

Quadro 1 - Descrição dos participantes da pesquisa

\begin{tabular}{|c|c|c|c|c|}
\hline Participante & Idade & $\begin{array}{c}\text { Nível de } \\
\text { Formação }\end{array}$ & $\begin{array}{c}\text { Tempo de serviço como } \\
\text { efetivo na instituição }\end{array}$ & $\begin{array}{c}\text { Tempo de trabalho na } \\
\text { Coordenação do NAPNE }\end{array}$ \\
\hline C1 & 52 & Mestrado & 30 anos & 15 anos \\
\hline C2 & 36 & Mestrado & 12 anos \\
\hline C3 & 41 & Especialização & 5 anos & 1 ano \\
\hline
\end{tabular}

Fonte: Elaborado pelas autoras, 2016.

\footnotetext{
${ }^{4}$ Os procedimentos adotados no presente estudo foram aprovados pelo Comitê de Ética em Pesquisa com Seres Humanos do IF pesquisado, conforme pareceres $\mathrm{n}^{\circ}$. 1.501.169 e $\mathrm{n}^{\circ} 1.840 .288$.
} 


\subsection{Os instrumentos}

A entrevista foi escolhida como instrumento de coleta de dados, por ser, segundo Gil (1989), um recurso flexível e muito utilizado na investigação social, "[...] indicado quando a natureza da informação se tratar de fenômeno que ficaria difícil ou impossível de ser observado" (MANZINI, 2004, p. 4).

Desse modo, as entrevistas foram semiestruturadas, com utilização de roteiro previamente elaborado, e realizadas com os coordenadores dos NAPNEs em seus locais de trabalho.

Os dados coletados a partir delas foram analisados numa perspectiva crítico-dialética, com base nos referenciais adotados neste estudo, e através do método de análise de conteúdo proposto por Bardin (1977).

Análise de conteúdo, segundo Bardin, é:

Um conjunto de técnicas de análise das comunicações visando obter, por procedimentos, sistemáticos e objetivos de descrição do conteúdo das mensagens, indicadores (quantitativos ou não) que permitam a inferência de conhecimentos relativos às condições de produção/recepção (variáveis inferidas) destas mensagens (BARDIN, 1977, p. 42).

A análise de conteúdo organizou-se em três passos ordenados, conforme definidos por Bardin (1977, p. 95), "pré-análise, exploração do material e tratamento dos resultados, a inferência e a interpretação".

Assim, o delineamento da pesquisa, conforme apresentado no Quadro 2, foi se configurando ao longo da investigação, com a definição de categorias e subcategorias, sendo constituída a partir da análise dos documentos institucionais, registros, falas dos participantes e inferências sobre as mesmas.

Quadro 2 - Esboço da pesquisa

\begin{tabular}{|c|c|c|c|}
\hline Objetivos & Fonte de análise & Categorias temáticas & Subcategorias \\
\hline \multirow{8}{*}{$\begin{array}{l}\text { Identificar } \\
\text { principais } \\
\text { potencialidades e } \\
\text { limitações } \\
\text { encontradas no } \\
\text { processo de inclusão } \\
\text { e atendimento aos } \\
\text { discentes público- } \\
\text { alvo da educação } \\
\text { especial em um } \\
\text { determinado IF }\end{array}$} & \multirow{2}{*}{$\begin{array}{l}\text { Documentos } \\
\text { institucionais }\end{array}$} & \multirow[t]{2}{*}{$\begin{array}{l}\text { Desenvolvimento das } \\
\text { ações inclusivas no IF }\end{array}$} & $\begin{array}{c}\text { Previsões de ações inclusivas } \\
\text { nos documentos institucionais } \\
\text { mais amplos }\end{array}$ \\
\hline & & & $\begin{array}{l}\text { Organização da prática } \\
\text { inclusiva nos campi }\end{array}$ \\
\hline & \multirow{6}{*}{$\begin{array}{l}\text { Entrevistas } \\
\text { semiestruturadas } \\
\text { realizadas com os } \\
\text { coordenadores de } \\
\text { NAPNEs (gravadas e } \\
\text { transcritas) }\end{array}$} & \multirow{2}{*}{$\begin{array}{l}\text { Concepções sobre } \\
\text { inclusão na educação } \\
\text { profissional e } \\
\text { tecnológica }\end{array}$} & $\begin{array}{l}\text { Compreensões sobre inclusão e } \\
\text { público-alvo da educação } \\
\text { especial }\end{array}$ \\
\hline & & & Possibilidades de inclusão \\
\hline & & \multirow{2}{*}{$\begin{array}{l}\text { Gestão e organização das } \\
\text { ações inclusivas }\end{array}$} & $\begin{array}{l}\text { Estrutura física, recursos } \\
\text { financeiros e materiais }\end{array}$ \\
\hline & & & $\begin{array}{l}\text { Recursos } \quad \text { humanos } \\
\text { qualificação para o trabalho }\end{array}$ \\
\hline & & \multirow{2}{*}{$\begin{array}{l}\text { Perspectivas do trabalho } \\
\text { inclusivo }\end{array}$} & $\begin{array}{l}\text { Dificuldades e facilidades no } \\
\text { processo inclusivo }\end{array}$ \\
\hline & & & $\begin{array}{l}\text { Ações necessárias, } \\
\text { possibilidades de melhorias }\end{array}$ \\
\hline
\end{tabular}

Fonte: Elaborado pelas autoras, 2016. 


\section{Resultados e discussão}

\subsection{O desenvolvimento das ações inclusivas no IF Sudeste MG}

Para auxiliar na compreensão da realidade vivida na instituição pesquisada, sob a ênfase do desenvolvimento da educação inclusiva, buscou-se uma análise apurada de seus documentos institucionais (BRASIL, 2011, 2011 a, 2011b, 2011c, 2011d, 2011e, 2011f, 2011g, 2011h, 2014, 2015a), com o intuito de mensurar as preocupações e garantias, existentes ou não, considerando aspectos da estrutura organizacional, das previsões, metas e perspectivas da instituição para com o trabalho inclusivo.

Ao analisar os documentos institucionais mais amplos, que contemplam a instituição pesquisada como um todo (todos seus campi e reitoria), verifica-se, nos mais recentes, a previsão de ações voltadas para o desenvolvimento de políticas para o atendimento aos discentes que são o público-alvo da educação especial (BRASIL, 2014, 2015a).

Nesse sentido, destaca-se o Plano de Desenvolvimento Institucional (PDI), que data de setembro de 2014, no qual há previsão de desenvolvimento de políticas de inclusão voltadas para pessoas com necessidades específicas, inserido como meta para atingir os objetivos associados à excelência acadêmica e tendo como indicadores a Regulamentação das Ações Inclusivas junto aos órgãos colegiados da instituição e a elaboração de um Plano de Inclusão para subsidiar e orientar as ações a serem desenvolvidas (BRASIL, 2014).

O Regimento Interno da Reitoria do IF Sudeste MG, de outubro de 2011, apresenta, como competência da Pró-Reitoria de Ensino, a proposição de políticas e diretrizes de educação inclusiva que contemplem toda a diversidade dos estudantes. Dessa maneira, contempla a existência de uma Coordenação de Ações Inclusivas para atuação em prol da inclusão e atendimento aos discentes público-alvo da educação especial. Essa coordenação também é vinculada à Pró-Reitoria de Ensino e possui como uma de suas atribuições apoiar os NAPNEs dos campi (BRASIL, 2011h).

O Projeto Político-Pedagógico Institucional, que é parte constituinte do PDI, apresenta a existência de um órgão colegiado assessor à Pró-Reitoria de Ensino, o Fórum de Ações Inclusivas, composto por um representante de cada campus e estando sob a orientação da Coordenação de Ações Inclusivas da Pró-Reitoria de Ensino. Segundo o documento citado, esse Fórum trabalharia na construção de um Plano de Inclusão Institucional, que "[...] definirá ações e atores envolvidos, a fim de que a instituição adote um conjunto de ações inclusivas visando à garantia do amplo ingresso, da permanência e da saída com êxito de seus discentes" (BRASIL, 2014, p. 52).

Outro documento institucional mais recente registra a preocupação com o atendimento às necessidades dos estudantes público-alvo da educação especial, o Regulamento de Conduta Discente, em vigor desde os meses finais do ano de 2015, mesmo ano em que é aprovado, no país, o Estatuto da Pessoa com Deficiência (BRASIL, 2015). Tal documento dedica um capítulo para tratar dos direitos específicos dos discentes público-alvo da educação especial, retomando algumas garantias conquistadas na legislação brasileira, como garantia de acessibilidade, física, pedagógica e de informação, apoio educacional e pedagógico especializado, recursos de tecnologia assistiva, adequações curriculares e planos de desenvolvimento individual (BRASIL, 2015a).

Entretanto, apesar de todas essas previsões contidas nos documentos institucionais, é possível apreender que, em sua maioria, elas resumem-se a proposições e perspectivas para o 
trabalho inclusivo, sem, no entanto, refletirem na organização de práticas nos campi. Essa interpretação ampara-se, ainda, na observação da ausência de previsões nos documentos institucionais mais específicos, de organização acadêmica e pedagógica, como os Regulamentos Acadêmicos (BRASIL, 2013b, 2016a), que não apontam qualquer orientação para organização e realização de ações que considerem as especificidades dos discentes público-alvo da educação especial nas práticas pedagógicas e docentes.

As previsões nos documentos não garantem o atendimento especializado aos discentes público-alvo da educação especial na prática. Assim, faltam registros de esforços e ações para construção de uma política interna, a qual direcione as ações que possibilitem, efetivamente, incluir os discentes público-alvo da educação especial no cotidiano escolar, assegurando-lhes os direitos que a legislação nacional já lhes garante.

Portanto, partindo para a análise dos documentos organizacionais mais específicos de cada campus do IF pesquisado (BRASIL, 2011, 2011a, 2011b, 2011c, 2011d, 2011e, 2011f, 2011g), é possível identificar referências a algumas estruturas de apoio organizadas para atender aos discentes público-alvo da educação especial, principalmente referenciadas pelo Programa TEC NEP que, conforme já mencionado, foi extinto. Desse modo, foi possível verificar que cinco dos dez campi que compõem o IF Sudeste MG possuem um NAPNE pelo menos previsto em seus documentos internos, estando em funcionamento apenas três deles, os quais encontram-se nos três maiores e mais antigos campi da instituição, conforme detalhado no Quadro 3.

Quadro 3 - Identificação de estruturas de apoio à educação especial existentes nos campi do IF

\begin{tabular}{|c|c|c|}
\hline \multirow{2}{*}{ CAMPUS } & \multicolumn{2}{|c|}{ DOCUMENTOS INSTITUCIONAIS ANALISADOS } \\
\hline & ORGANOGRAMA & REGIMENTO INTERNO \\
\hline Barbacena & $\begin{array}{l}\text { Existência de uma Coordenação } \\
\text { de Educação Inclusiva vinculada } \\
\text { à Diretoria de Ensino. }\end{array}$ & $\begin{array}{l}\text { Existência de uma Coordenação de Educação Inclusiva } \\
\text { vinculada à Diretoria de Ensino. Faz referência ao } \\
\text { NAPNE, indicando, porém, que tem regulamentação } \\
\text { própria. }\end{array}$ \\
\hline Juiz de Fora & $\begin{array}{l}\text { Existência do NAPNE, } \\
\text { vinculado diretamente à } \\
\text { Diretoria de Extensão e Relações } \\
\text { Comunitárias. }\end{array}$ & Não há referência alguma. \\
\hline Rio Pomba & $\begin{array}{l}\text { Existência do NAPNE, } \\
\text { vinculado à Diretoria de Ensino. }\end{array}$ & $\begin{array}{l}\text { Existência do NAPNE, vinculado à Coordenação Geral de } \\
\text { Assistência Estudantil, que, por sua vez, está vinculada à } \\
\text { Diretoria de Ensino. }\end{array}$ \\
\hline $\begin{array}{l}\text { São João del- } \\
\text { Rei }\end{array}$ & Não possui & $\begin{array}{l}\text { Não faz referência ao NAPNE, no entanto, faz referência } \\
\text { a três setores corresponsáveis pelas ações inclusivas, } \\
\text { divididos em perspectivas de ação: educacional, atitudinal } \\
\text { e arquitetônica. }\end{array}$ \\
\hline Muriaé & Não possui & $\begin{array}{l}\text { Existência do NAPNE, com descrição de suas funções, } \\
\text { como vinculado à Coordenação Geral de Assistência ao } \\
\text { Educando, que, por sua vez, está vinculada à Diretoria de } \\
\text { Pesquisa e Extensão. }\end{array}$ \\
\hline $\begin{array}{c}\text { Santos } \\
\text { Dumont }\end{array}$ & Não possui & Em construção \\
\hline Bom Sucesso & Não possui & Não possui \\
\hline Manhuaçu & Não possui & Não possui \\
\hline Ubá & Não possui & Não possui \\
\hline Cataguases & Não possui & Não possui \\
\hline
\end{tabular}

Fonte: Elaborado pelas autoras, 2016. 
É possível concluir que os campi São João del-Rei e Muriaé, apesar de não possuírem os núcleos atuantes, já possuíram, em outro momento, visto que esses campi foram criados antes da extinção do programa TEC NEP, em 2011. Já os demais campi, de constituição mais recente, não chegaram a institucionalizar, em momento algum, o NAPNE, provavelmente em razão da extinção do programa que o propunha, da falta de incentivo institucional, da falta de profissionais com capacitação ou formação na área e de uma política específica da instituição para impulsionar as ações de inclusão.

Os três NAPNEs existentes mantêm os propósitos de organização conforme orientação do programa governamental que os implementou, entretanto, na prática, adquiriram configurações próprias, possivelmente, devido à extinção do programa, à falta de referência governamental e à falta de incentivo dada ao setor pela própria instituição.

Nesse sentido, é possível observar que os NAPNEs, um pouco diferentemente do que tem ocorrido em outras instituições, como, por exemplo, no Instituto Federal de Educação, Ciência e Tecnologia do Rio de Janeiro, descrito no estudo de Carlou (2014), e no Instituto Federal de Educação, Ciência e Tecnologia Sul-Rio-Grandense, descrito nos estudos de Pereira (2011, 2016), se mantêm com base na "boa intenção" ou na sensibilidade individual pelo tema da inclusão por parte de um ou dois servidores, sem muito reconhecimento e/ou respaldo institucional. Tal constatação é respaldada materialmente pela inexistência de ao menos um regulamento institucional para o funcionamento e exercício dos NAPNEs no IF Sudeste MG.

Contudo, os discentes que necessitam de um setor ou núcleo de referência e apoio da educação especial dentro da instituição acessam os mais diversos níveis de ensino no IF, exigindo, cada vez mais, reconhecimento e retorno da instituição.

\subsection{Concepções sobre inclusão na educação profissional e tecnológica}

Os coordenadores de NAPNEs entrevistados possuem concepções um pouco diferenciadas sobre a educação inclusiva. Enquanto um concebe como reconhecimento de necessidades, outro identifica como questão de direito e cidadania, e o terceiro, por sua vez, como questão de humanidade, conforme expressam em suas falas:

Então, a educação inclusiva hoje, para mim, é aquela em que a gente precisa reconhecer quais são as necessidades reais da pessoa que precisa adquirir educação, conhecimento (Entrevista, C1).

Eu penso que é uma forma de propiciar oportunidades, de forma igualitária, para todas as pessoas que têm alguma necessidade especial, por ventura, mas é principalmente a garantia de direitos das pessoas (Entrevista, C2).

[...] inclusão é você ser humano com o outro que entra aqui dentro da escola (Entrevista, C3).

Conforme ratifica a Declaração de Salamanca (UNESCO, 1994), a educação inclusiva expressa-se no conjunto destas afirmações colocadas pelos entrevistados.

Qualquer pessoa portadora de deficiência tem o direito de expressar seus desejos com relação à sua educação, tanto quanto estes possam ser realizados. [...] Escolas 
inclusivas devem reconhecer e responder às necessidades diversas de seus alunos, acomodando ambos os estilos e ritmos de aprendizagem e assegurando uma educação de qualidade a todos através de um currículo apropriado, arranjos organizacionais, estratégias de ensino, uso de recurso e parceria com as comunidades (UNESCO, 1994, p. 3 e 5$)$.

Destarte, ressalta-se a importância de promover oportunidades de compartilhamento de compreensões, de discursos e de práticas entre os servidores, como é o caso dos coordenadores de NAPNE, de modo que tenham oportunidade de troca com seus pares, para fortalecer suas concepções e ações.

Ainda sobre a conceituação da educação inclusiva, segundo Bergamo (2009, p. 55), a escola inclusiva é a escola para todos, que não faz distinção, que supera a exclusão, "uma escola que respeita as diferenças individuais de cada aluno, que encontra respostas educativas às suas necessidades especiais, sem deixar de atender os demais."

Ademais, educação inclusiva é um direito básico ofertado para todos em escolas e salas de aula onde todas as necessidades dos discentes sejam atendidas (STAINBACK; STAINBACK, 1999).

Apesar de nem todos os entrevistados terem vivenciado o programa governamental TEC NEP, eles compartilham de um mesmo entendimento sobre o público ao qual o trabalho dos núcleos é destinado, ou seja, que deve ser amplo, extrapolando o tendencioso direcionamento de atendimento restrito aos discentes com deficiência.

Esse posicionamento ratifica o previsto na Política Nacional de Educação Especial na Perspectiva Inclusiva, de que "as definições do público-alvo devem ser contextualizadas e não se esgotam na mera categorização e especificações atribuídas a um quadro de deficiência, transtornos, distúrbios e aptidões" (BRASIL, 2008, p.15).

Quando questionados sobre os propósitos dos núcleos e suas funções, novamente verifica-se a existência de uma compreensão quase que pacificada entre os coordenadores. Todos resumem o trabalho do NAPNE como o apoio aos discentes com necessidades específicas, na oferta de recursos e suporte para eles.

De acordo com os relatos dos coordenadores de NAPNEs da instituição, é possível identificar que o trabalho realizado pelos núcleos é bem próximo da concepção do Atendimento Educacional Especializado (AEE). Trata-se, portanto, de instrumentalizar os discentes atendidos através de suportes específicos para que possam acessar os conteúdos trabalhados em sala de aula (BRASIL, 2008).

Quando questionados sobre a possibilidade de praticar uma educação inclusiva em seus respectivos campi, que atenda às necessidades dos estudantes público-alvo da educação especial, todos consideraram ser possível, no entanto, algumas condições foram colocadas como essenciais para que isso ocorra:

Olha é.... nós temos que respeitar limitações, não temos como, por exemplo, pegar uma pessoa que seja cega e sair colocando ele na frente de um torno, para ele sair torneando uma peça, uma peça de alto giro ou uma peça perigosa, afiada. Então, quer dizer, não que ele não possa, não que ele não consiga, mas teria que ser feito um trabalho muito minucioso, muito dedicado, alguma coisa, assim, que fugiria necessariamente ao que a gente oferece hoje no nosso instituto. Não estou negando que ele poderia, mas não na realidade do nosso instituto, as formas que a gente tem 
hoje. Mas, eu não vejo restrições com relação a tentar trabalhar com a pessoa, desde que ela tenha interesse [...] (Entrevista, C1).

Eu acredito que é possível, mas eles precisam de uma base, né, senão não adianta um aluno entrar num técnico, né, num curso profissional, sem ele ter conhecimento do fundamental... se ele tiver sim! É uma inclusão tranquila, mas se ele não tiver base, como qualquer aluno sem deficiência... (Entrevista, C2).

Então, assim, eu acho que consegue, mas se não tiver vontade dos professores é difícil, não vou dizer que é impossível, que nada é impossível [...], mas se não tiver vontade dos professores... porque por mais que a gente trabalhe, se a gente não conseguir a acessibilização e a conscientização dos professores, a gente não consegue ter educação inclusiva na escola não (Entrevista, C3).

É interessante observar que os coordenadores de NAPNE não compartilham de uma mesma compreensão sobre o que falta, sobre aquilo que limita o desenvolvimento de uma prática efetivamente inclusiva.

C2 tem uma compreensão de que, se os discentes não tiverem uma base de conhecimentos mínimos, referente às etapas de ensino anteriores, para acesso ao ensino profissional, isso indica que a inclusão escolar se torna quase inviável nesta modalidade de ensino.

Já C1 indica certa impossibilidade de incluir, considerando as condições que o campus oferece, sem opor-se à tentativa de trabalho inclusivo a partir da condição de interesse do discente.

Com compreensão similar sobre a falta de condições da instituição para efetuar a prática inclusiva, C3 destaca a falta de interesse dos professores em contribuírem para essa prática, salientando que, sem o apoio desses profissionais, se torna impraticável a educação na perspectiva inclusiva.

Nesse aspecto, Glat e Pletsch (2012, p. 30) observaram que, apesar dos avanços alcançados nas políticas públicas de educação especial, muitas pesquisas realizadas no país evidenciam dificuldades de concretização dessas propostas nas práticas escolares, com destaque para a falta de formação/capacitação dos docentes para o trabalho inclusivo. Essa observação nos conduz a refletir sobre a falta de contribuição dos professores para a prática inclusiva, conforme relatado por C3, como resultado da falta de formação inicial ou continuada em educação especial e inclusiva.

Sabe-se que, para que a inclusão escolar realmente ocorra, é necessária uma mudança de paradigma educacional, que segundo Glat e Pletsch (2012, p. 75), "exige transformações profundas na organização e cultura escolares". Tal transformação não acontecerá sem os docentes, mas é preciso que eles tenham acesso à formação inicial e continuada na perspectiva da educação inclusiva e do trabalho com a diversidade.

Deste modo, os espaços escolares devem facilitar os processos de mudanças para promoção de ações inclusivas. É preciso sair da identificação de incompetência para o desenvolvimento de competência. É importante deixar de centralizar na burocracia para centralizar os esforços nos discentes. Ao invés de fugir das responsabilidades, é necessário promover a participação e buscar garantir as condições necessárias para que ocorra uma mudança de cultura do sistema escolar (STAINBACK; STAINBACK, 1999, p. 139 e 140).

Neste sentido, Glat e Pletsch (2012, p. 144) indicam, como algumas ações indispensáveis para reestruturação do ambiente e da dinâmica escolar, a "viabilização de 


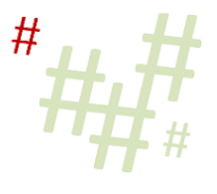

matrículas, ações afirmativas e linhas de financiamento para obras de acessibilidade, aquisição de material didático adaptado e formação de recursos humanos".

\subsection{Gestão e organização das ações inclusivas}

Nos relatos dos entrevistados sobre as estruturas, relativas a recursos físicos, materiais e financeiros, dos NAPNEs, foi possível verificar que, apesar de todos os três núcleos possuírem espaço físico adequado, que atendem às suas necessidades atuais, há dificuldades para aquisição de equipamentos e recursos de acessibilidade, sendo que, neste aspecto, os coordenadores $\mathrm{C} 1 \mathrm{e}$ $\mathrm{C} 2$ foram os que relataram maior dificuldade.

Dessa forma, destaca-se a importância da existência de um espaço físico apropriado, dotado de recursos mínimos, para oferecer apoio aos discentes público-alvo da educação especial, tendo como referência as salas de recursos multifuncionais, implementadas nas redes regulares de ensino, escolas públicas municipais e estaduais, e os Núcleos de Acessibilidade, implementados nas Universidades Federais, ambos como política pública de inclusão do MEC (BRASIL, 2010, 2013).

Já com relação a recursos humanos disponíveis, verifica-se que o núcleo coordenado por C3 encontra-se em melhor situação que os demais, dispondo de um servidor técnicoadministrativo lotado exclusivamente no núcleo. Observa-se também que C3 atua exclusivamente no núcleo, já que, como docente, encontra-se, atualmente, com impedimentos para retorno ao trabalho em sala de aula.

Além disso, C3 esclarece que conta com o apoio de alguns discentes que prestam serviços para o núcleo, como tutores ou monitores de outros estudantes que são acompanhados pelo NAPNE. Para isso, há recurso financeiro disponibilizado mensalmente pela instituição para dar suporte ao núcleo, através do pagamento de bolsas a esses tutores e monitores.

Todavia, os outros dois NAPNEs são compostos apenas pelos coordenadores, que exercem as atribuições de seus cargos, além do trabalho de coordenação do núcleo.

Segundo relatos de $\mathrm{C} 1$ e conforme proposta do extinto Programa TEC NEP (ANJOS, 2006; NUNES, 2012), os NAPNEs, em suas constituições, foram compostos por elevado número de servidores, dos diversos setores dos campi, que deveriam reunir-se para discutir propostas e atividades para implementação das ações inclusivas no seu contexto; no entanto, observou-se que, com o passar dos anos, houve um esvaziamento dos NAPNEs, que passaram a constituir-se apenas pelo seu coordenador, que, na maioria das vezes, ainda desempenhava outras atribuições relativas ao seu cargo.

Esse processo de esvaziamento, apesar de ter sido relatado apenas por C1, ocorreu também nos outros dois núcleos, que hoje possuem poucas pessoas atuantes. Tal fato pode ser identificado como uma demonstração do formato da proposta inicial do NAPNE, na concepção do Programa TEC NEP, e de como ele não teve o êxito esperado e/ou idealizado. Assim, a concepção e institucionalização do NAPNE, proposta pelo Programa TEC NEP, não pôde ser avaliada através dele, já que esse, conforme apresentam Nascimento e Faria (2013), foi extinto antes mesmo de ter finalizado todas as suas etapas de implementação.

Na ausência de referências do Programa TEC NEP e, na sequência, na ausência de destinação de recursos específicos para o trabalho com a acessibilidade e inclusão (BRASIL, 2013a), não restou outra solução às instituições da rede EPCT além da implementação dos núcleos dentro das suas possibilidades, dando característica particular a cada um, seja no modo de organização ou de efetivação do trabalho. 
Quando questionados sobre a formação e/ou qualificação em educação especial e inclusiva dos servidores envolvidos no trabalho do núcleo, considerando, para isso, a participação em qualquer curso de formação/capacitação ou mesmo participação em disciplinas sobre o tema durante a formação, o retorno que obtivemos foi de que apenas C2 possui uma especialização na área de educação inclusiva e de que $\mathrm{C} 1$ realizou uma capacitação em Braille, no Instituto Benjamin Constant.

Logo, cumpre destacar a importância da formação destes profissionais, que se apresentam como referência da educação inclusiva em seus campi e que precisam empoderarse, através do conhecimento, para defenderem e reivindicarem práticas educativas mais inclusivas, as quais respeitem a diversidade dos estudantes.

Neste sentido, torna-se imprescindível o trabalho formativo dos profissionais lotados nos núcleos, de modo que esses possam disseminar seus conhecimentos e os propósitos da cultura inclusiva na instituição.

\subsection{Perspectivas do trabalho inclusivo}

No período de realização das entrevistas, foram identificados/declarados, aproximadamente, 15 alunos como público-alvo da educação especial, que eram atendidos pelos três núcleos da instituição.

Apenas C2 acredita que não tem atendido satisfatoriamente às necessidades dos discentes, porque sempre trabalha com medidas paliativas, uma vez que, em virtude, muitas vezes, de questões burocráticas, não consegue as melhores soluções e os recursos que os discentes necessitam. Já $\mathrm{C} 1$ e C3 acreditam que o núcleo, dentro de suas possibilidades, tem atendido satisfatoriamente os discentes.

[...] a gente não consegue alguns recursos para atender alunos, por exemplo, a gente não consegue cadeira de rodas. A acessibilidade, infelizmente, a gente teve que mudar a sala onde uma cadeirante participa das aulas, isso porque não tem acesso ao prédio, então a gente mudou ela de prédio, a gente mudou a turma dela de prédio, né. Justamente por conta da acessibilidade. Foi solicitado um passeio para que ela chegasse até a sala de aula e não foi feito. As solicitações de demanda, por exemplo: o intérprete, né, tradutor... A menina entrou em fevereiro, nós tivemos que atendê-la usando o celular né, usando o Hand talk, porque nós não tínhamos intérprete e ainda não temos [..] (Entrevista, C2).

Dentre os coordenadores entrevistados, apenas C3 destaca, de forma objetiva, como observa os pontos positivos do trabalho do NAPNE refletido nos discentes atendidos e acompanhados:

\footnotetext{
Ah! Eu observo! Eu estou observando, assim, é o que acontece, em conselho de classe que eu já participei, de professores falarem que o aluno tal, depois que ele teve apoio de uma professora, né, de apoio, que ele se destacou mais. Eu vejo assim, que o desenvolvimento de outro aluno atendido com o aprendizado em matemática, que ele conseguiu passar na disciplina de cálculo, na qual ele tinha sido reprovado. Que assim, se não tivesse essa iniciação científica, esse apoio, esse aluno nunca ia conseguir passar em matemática, esse aluno ia o quê? Ele não ia conseguir conquistar um aprendizado, ele ia ser empurrado (Entrevista, C3).
} 
Neste aspecto, $\mathrm{C} 1$ focou muito nos pontos negativos, esquecendo-se de ressaltar o que observava de positivo, apenas concluindo como um trabalho satisfatório, e C2 observou outro lado positivo, o da convivência com as diferenças.

Sim, a melhor delas é com relação aos alunos que não têm deficiência e nos ajudam, e não só nos projetos, mas também que auxiliam em sala de aula, porque eles dão suporte. Esses alunos auxiliam por vontade própria [...] acho isso excelente, eu vejo isso como o ponto positivo da inclusão (Entrevista, C2).

Quando os entrevistados foram indagados sobre as dificuldades que eles encontram no processo inclusivo, C3 retomou a questão da importância do envolvimento e da responsabilização do professor, conforme já havia indicado quando questionado sobre as possibilidades de a instituição ser realmente inclusiva. Assim, C3 acredita que, com base em sua experiência, a maior dificuldade no processo inclusivo é o comprometimento de todos os professores para com a inclusão:

Então, eu acho que nosso maior desafio, nossa maior dificuldade chama-se professor [...]. Se o professor não enxergar esse aluno dentro de sala de aula, ele vai passar por aqui como ele vem passando por outras escolas, sem aprender nada. Então, a dificuldade maior que eu acho que a gente tem, não só aqui, mas na educação inclusiva como um todo, chama-se professor, porque muitos não querem. É... Não acham que esse aluno deveria estar aqui (Entrevista, C3).

Já C1 menciona uma série de dificuldades de ordens material e física, mas também dá destaque para a questão do envolvimento e comprometimento dos professores na realização de adaptações para atendimento aos discentes público-alvo da educação especial:

[...] a gente tinha que estar num lugar mais reservado, às vezes a pessoa vai ser atendida, mas ela fica com vergonha, pois pensa que todo mundo vai ver ela entrando no NAPNE [...] A área do setor é até boa, a sala tem um tamanho bacana. Mas, assim, precisávamos ter outras coisas, precisávamos, por exemplo, ter um material mais adaptado, uma lupa maior. Coisa assim que precisa. [...] Então, você vê que as dificuldades que a gente encontra... a maioria delas é convencer, convencer não é a palavra, mas incentivar as pessoas a deixar um pouco de lado esse medo [...] Somos educadores, a gente está dentro de um ambiente que o tempo todo vai ter gente diferente. Então, não é porque a pessoa é surda ou cega, é qualquer um, pessoas que tenham uma origem diferente, um conhecimento diferente, ele vai ter necessidade de adaptação (Entrevista, C1).

De certo modo, corroborando com C3 e C1, C2 destaca, como a maior dificuldade no processo educacional inclusivo, a questão atitudinal, de estranhamento e de desconhecimento, das pessoas que têm dividido o mesmo espaço acadêmico com discentes considerados "diferentes", discentes público-alvo da educação especial. Essa abordagem pode ser associada à manifestação dos demais coordenadores sobre a atitude dos docentes para com esse público.

Sobre as possibilidades e necessidades de melhorias, todos os coordenadores indicam algumas melhorias necessárias, com base em suas experiências e realidades. Destacam-se os itens de melhoria indicados por mais de um coordenador, como a necessidade de envolvimento 
de mais pessoas no trabalho e de investimento em melhores condições de acessibilidade, em mais suportes e em equipamentos a serem disponibilizados.

Quanto às sugestões que eles dariam para o alcance das melhorias indicadas:

[...] eu não sei exatamente, mas assim, a gente precisa de ter uma equipe preparada e precisa também de um apoio a esse aluno que chega, no que tange a parte educacional, a básica, já que ele vai chegar, assim, sem fundamento. Ele precisa de um ensino básico, mas eu não sei se caberia isso a nós, acho que isso tem que ser pensado né. [...] se a gente pudesse oferecer os recursos que uma escola especial oferece, eu acho que também contribuiria. [...] Mas, eu vejo que quanto mais pessoas trabalhando na causa, mais apoio. Acho que mais êxito a gente teria, né, mais resultados [...]. O aluno precisa do suporte especializado para além da sala de aula no IF e nas escolas especiais, ambas têm que manter uma conversa. O currículo do jeito que funciona hoje, até para os alunos que não têm deficiência, ele precisa ser repensado. Esse currículo não visa mesmo, eu acho, o desenvolvimento pleno do educando, infelizmente (Entrevista, C2).

Do jeito que está hoje, está bom para a demanda que a gente tem, mas à medida que essa demanda for aumentando a gente tem que tentar melhorar mais. Igual você perguntou: o que você acha que pode ser feito para melhorar? [...]. Eu quero criar um núcleo de apoio do NAPNE [...] NAPNE dialoga. Então, assim, estou pensando para a gente crescer mais e conhecer mais os nossos alunos com necessidades específicas (Entrevista, C3).

\begin{abstract}
Acho que precisamos de mais equipamentos, de mais verba [...]. Então, se a gente conseguisse fazer uns cursinhos, ou alguma coisa mais direcionada para os educadores, que vão lidar com a turma o tempo todo, seria interessante, mas assim, já fizemos propostas, e cadê gente aparecendo? [...]. O núcleo dentro do campus é sumariamente importante [...] e nada melhor do que uma pessoa que está ali, no contato diário, no corpo a corpo para entender. Acredito seria muito importante que cada campus tenha o seu núcleo, o NAPNE [...]. Então, realmente seria muito, muito bom que os outros campi também tivessem o núcleo, ainda que não tivesse o núcleo, que não tivesse o ambiente, mas que tivesse uma pessoa (Entrevista, C1).
\end{abstract}

Apesar de todas as limitações, anseios e necessidades destacados pelos entrevistados para a efetivação de práticas mais inclusivas, numa análise mais minuciosa de seus relatos e da realidade institucional, é possível depreender também alguns pontos favoráveis ao desenvolvimento de uma política educacional inclusiva. Assim, a começar pelo trabalho que já vem sendo realizado nos três núcleos existentes, que, mesmo desprovidos de recursos humanos e financeiros, têm procurado atender às necessidades dos discentes, buscando alternativas e soluções para as situações apresentadas. Além disso, a existência e funcionamento do NAPNEs, mesmo sem uma referência política maior ou mesmo diretrizes institucionais, evidencia uma preocupação com os estudantes público-alvo da educação especial.

Nesse sentido, C2 relata vários projetos de extensão, que ocorrem ou já ocorreram em seu campus de lotação, em parceria com instituições de atendimento a pessoas com deficiência ou outros, no intuito de favorecer não apenas a comunidade externa, mas também a própria comunidade escolar, que se beneficia com grande aprendizado nessa relação.

Ainda nessa perspectiva, C3 indica a realização de um projeto de pesquisa, com estudantes de um curso de licenciatura, em seu campus, para o desenvolvimento de estratégias de ensino para um discente cego matriculado na instituição. 
Dessa forma, fica ainda mais evidente a possibilidade de desenvolvimento de novos recursos e alternativas para atender às necessidades dessa parcela da população, através de projetos de pesquisa, além da realização de parcerias com a comunidade externa e instituições especializadas no atendimento ao público-alvo da educação especial, através de projetos de extensão, e do desenvolvimento do ensino para a diversidade.

\section{Considerações finais}

O processo investigativo, portanto, possibilitou compreender a complexidade do processo de inclusão e permanência dos estudantes público-alvo da educação especial e identificar algumas limitações na instituição pesquisada, como a falta de organização sistêmica do trabalho com inclusão e de direcionamentos específicos para o trabalho inclusivo, resultando em ausência de diretrizes para organização das práticas inclusivas.

Tal constatação justifica o não estabelecimento, no IF Sudeste MG, de uma cultura inclusiva que permeie todos os âmbitos e ações institucionais e que coloque a acessibilidade e a inclusão como parâmetros para qualquer prática.

Nessa perspectiva, foi possível identificar outros elementos que dificultam o processo inclusivo, como a falta de capacitação dos servidores sobre a temática da educação inclusiva, a escassez de investimentos por parte da instituição, tanto em recursos humanos como em recursos materiais, e, por fim, a questão atitudinal, do preconceito e desresponsabilização dos profissionais para com o estudante público-alvo da educação especial.

No entanto, também foram observados pontos positivos para o desenvolvimento do processo educacional pelo viés da inclusão. A começar pelas próprias diretrizes de trabalho concebidas para a atuação da Rede EPCT, com vistas a privilegiar o desenvolvimento local, econômico e social, primando pelo desenvolvimento da cidadania, equidade e pela redução das desigualdades (BRASIL, 2010a).

Ademais, pela sua característica organizacional, de oferta de diversas modalidades de ensino, a instituição conta com a contribuição de profissionais de diversas áreas de formação, possibilitando o trabalho multiprofissional para o atendimento mais rico e eficaz ao públicoalvo da educação especial. Sem contar, ainda, o potencial para o trabalho inclusivo que pode ser estimulado através da articulação entre ensino, pesquisa e extensão.

Do mesmo modo, a manutenção e funcionamento de alguns NAPNEs que, mesmo sem ter um referencial político/orientador e profissionais especializados na área de educação especial e inclusiva, buscam, da melhor maneira possível, atender às demandas dos estudantes público-alvo da educação especial que ingressam na instituição constitui fonte de reconhecimento, de inspiração e, principalmente, de potencialidade para expansão do trabalho inclusivo.

À vista disso, o processo reflexivo exercitado neste artigo possibilitou a compreensão de que é necessário e possível que a instituição pesquisada se (re)organize para a promoção da educação inclusiva. Todavia, é premente que haja um movimento institucional de quebra de paradigmas, de superação de preconceitos e de mudança de cultura, de maneira que, mesmo diante da falta de direcionamento e incentivo governamental, se possa priorizar e investir em um processo educacional mais inclusivo. 


\section{Referências}

ANJOS, Isa Regina Santos dos. 2006. Programa TEC NEP: avaliação de uma proposta de educação profissional inclusiva. Dissertação (Mestrado em Educação Especial) - Centro de Educação e Ciências Humanas, Universidade Federal de São Carlos, São Paulo, 2006.

BARDIN, Laurence. Análise de Conteúdo. Lisboa: Editora setenta, 1977. 225 p.

BERGAMO, Regiane Banzzatto. Pesquisa e prática profissional: educação especial. Curitiba: IBPEX, 2009. 104p.

BRASIL. Ministério da Educação. Política Nacional da Educação Especial na Perspectiva da Educação Inclusiva. Brasília, 2008.

BRASIL. Ministério da Educação. Resolução CNE/CEB n 04/2010. Diretrizes Curriculares Nacionais da Educação Básica. Brasília, 2010. Disponível em: < http://portal.mec.gov.br/dmdocuments/rceb004_10.pdf >. Acesso em: 10 jun. 2016.

BRASIL. Ministério da Educação. Secretaria de Educação Profissional e Tecnológica. Concepção e diretrizes dos Institutos Federais. Brasília, 2010a. Disponível em: $<$ http://portal.mec.gov.br/index.php?option=com_docman\&view=download\&alias=6691-ifconcepcaoediretrizes\&category_slug=setembro-2010-pdf\&Itemid=30192> Acesso em: 13 nov. 2015.

BRASIL. Ministério da Educação. Instituto Federal de Educação, Ciência e Tecnologia do Sudeste de Minas Gerais. Regimento Interno Campus Barbacena. Barbacena, maio de 2011. Disponível em:

<http://www.barbacena.ifsudestemg.edu.br/sites/default/files/resolucao_022_regimento_inter no_campus_barbacena.pdf>. Acesso em: 02 mar. 2016.

BRASIL. Ministério da Educação. Instituto Federal de Educação, Ciência e Tecnologia do Sudeste de Minas Gerais. Estrutura Organizacional - Campus Barbacena. Barbacena, outubro de 2011a. Disponível em:

<http://www.barbacena.ifsudestemg.edu.br/sites/default/files/apresentacao-organogramacampus-barbacena-28-10-2011.pdf>. Acesso em: 02 mar. 2016.

BRASIL. Ministério da Educação. Instituto Federal de Educação, Ciência e Tecnologia do Sudeste de Minas Gerais. Regimento Interno Campus Juiz de Fora. Juiz de Fora, maio de 2011b. Disponível em:

<http://www.jf.ifsudestemg.edu.br/documentos/REGIMENTO_INTERNO_FINAL.pdf>. Acesso em: 02 mar. 2016.

BRASIL. Ministério da Educação. Instituto Federal de Educação, Ciência e Tecnologia do Sudeste de Minas Gerais. Estrutura Organizacional - Campus Juiz de Fora. Juiz de Fora, 2011c. Disponível em:

<http://www.jf.ifsudestemg.edu.br/documentos/ORGANOGRAMA_2011.pdf> Acesso em: 02 mar. 2016.

BRASIL. Ministério da Educação. Instituto Federal de Educação, Ciência e Tecnologia do Sudeste de Minas Gerais. Regimento Interno Campus Rio Pomba. Rio Pomba, março de 
2011d. Disponível em:

<http://www.riopomba.ifsudestemg.edu.br/portal/sites/default/files/arq_paginas/Reg_Interno_ RP.pdf>. Acesso em: 02 mar. 2016.

BRASIL. Ministério da Educação. Instituto Federal de Educação, Ciência e Tecnologia do Sudeste de Minas Gerais. Estrutura Organizacional - Campus Rio Pomba. Rio Pomba. 2011e. Disponível em: <http://www.riopomba.ifsudestemg.edu.br/portal/node/3> Acesso em: 02 mar. 2016.

BRASIL. Ministério da Educação. Instituto Federal de Educação, Ciência e Tecnologia do Sudeste de Minas Gerais. Regimento Interno Campus São João del-Rei. São João del-Rei, março de 2011f. Disponível em: <

http://www.sjdr.ifsudestemg.edu.br/sites/default/files/Regimento\%20Interno\%20SJDR.pdf>. Acesso em: 02 mar. 2016

BRASIL. Ministério da Educação. Instituto Federal de Educação, Ciência e Tecnologia do Sudeste de Minas Gerais. Regimento Interno Campus Muriaé. Muriaé, fevereiro de 2011g. Disponível em: <

http://www.muriae.ifsudestemg.edu.br/sites/default/files/regimento_interno_retificado.pdf >. Acesso em: 02 mar. 2016

BRASIL. Ministério da Educação. Instituto Federal de Educação, Ciência e Tecnologia do Sudeste de Minas Gerais. Regimento Interno Reitoria do IF Sudeste MG. Minas Gerais, 2011h. Disponível em: <

http://www.ifsudestemg.edu.br/sites/default/files/REGIMENTO\%20INTERNO\%20REITORI A\%20vers\%C3\%A3o\%20aprovada\%20pelo\%20CONSU_1.pdf >. Acesso em: 29 fev. 2016.

BRASIL. Ministério da Educação. Documento Orientador Programa Incluir acessibilidade na educação superior. SECADI/SESU. Brasília, 2013. Disponível em: $<$ http://portal.mec.gov.br/index.php?option=com_docman\&view=download\&alias $=12737$ -documento-orientador-programa-incluir-pdf\&category_slug=marco-2013pdf\&Itemid=30192> . Acesso em: 09 set. 2015.

BRASIL. Ministério da Educação. Secretaria de Educação Continuada, Alfabetização, Diversidade e Inclusão. Nota Técnica no 106 de 19 de agosto de 2013. Orientação à Implementação da Política Institucional de Acessibilidade na Rede Educação Profissional Científica e Tecnológica. Brasília, 2013a.

BRASIL. Ministério da Educação. Instituto Federal de Educação, Ciência e Tecnologia do Sudeste de Minas Gerais. Regulamento Acadêmico dos Cursos de Educação Profissional Técnica de Nível Médio do IF Sudeste MG. Minas Gerais, abril de 2013b. Disponível em: https://www.ifsudestemg.edu.br/pro_reitorias Acesso em: 8 ago. 2016.

BRASIL. Ministério da Educação. Instituto Federal de Educação, Ciência e Tecnologia do Sudeste de Minas Gerais. Plano de Desenvolvimento Institucional (PDI), 2014/2 - 2019. Minas Gerais, setembro de 2014. Disponível em: <http://www.ifsudestemg.edu.br/sites/default/files/pdi_2014_2019_0.pdf> Acesso em: 28 fev. 2016. 
BRASIL. LEI N 13.146, de 6 de julho de 2015. Institui a Lei Brasileira de Inclusão da Pessoa com Deficiência. Brasília, 2015.

BRASIL. Ministério da Educação. Instituto Federal de Educação, Ciência e Tecnologia do Sudeste de Minas Gerais. Regulamento de Conduta Discente. Minas Gerais, novembro de 2015a. Disponível em: < https://www.ifsudestemg.edu.br/sites/default/files/REGULAMENTO\%20DE\%20CONDUTA \%20DISCENTE\%20-\%20Aprovado\%20CONSU\%20-\%2025-03.pdf > Acesso em: 28 fev. 2016.

BRASIL. Sistema Nacional de Informações da Educação Profissional e Tecnológica SISTEC. Instituto Federal de Educação, Ciência e Tecnologia do Sudeste de Minas Gerais. Minas Gerais, outubro de 2016.

BRASIL. Ministério da Educação. Instituto Federal de Educação, Ciência e Tecnologia do Sudeste de Minas Gerais. Regulamento Acadêmico de Graduação do IF Sudeste MG. Minas Gerais, junho de 2016a. Disponível em: https://www.ifsudestemg.edu.br/pro_reitorias Acesso em: 8 ago. 2016.

CARLOU. Amanda. Inclusão na educação profissional: visão dos gestores do IFRJ. 2014. Dissertação (Mestrado em Educação) - Programa de Pós-graduação em Educação, da Universidade do Estado do Rio de Janeiro. Rio de Janeiro, 2014.

GIL, Antônio Carlos. Métodos e Técnicas de Pesquisa Social. 2 ed. São Paulo: Atlas, 1989. $206 \mathrm{p}$.

GLAT, Rosana; PLETSCH, Márcia Denise. Inclusão escolar de alunos com necessidades especiais. 2 ed. Rio de Janeiro: EdUERJ, 2012. 164 p.

MANZINI, Eduardo José. Entrevista Semi-estruturada: Análise de Objetivos e de Roteiros. In: Seminário internacional de pesquisa e estudos qualitativos. 2., 2004, Bauru. Anais... Bauru: SE\&PQ, 2004. Disponível em:

< http://www.sepq.org.br/IIsipeq/anais/pdf/gt3/04.pdf>. Acesso em: 03 fev. 2016.

MEC. Secretaria de Educação Continuada, Diversidade e Inclusão. Programas e Ações.

2014. Disponível em: <http://portal.mec.gov.br/secretaria-de-educacao-continuadaalfabetizacao-diversidade-e-inclusao/programas-e-acoes> Acesso em: 10 nov. 2016.

MINAYO, Maria Cecília de Souza (Org.). Pesquisa Social: teoria, método e criatividade. 34. ed. Petrópolis, RJ: Vozes, 2015. 108 p.

NASCIMENTO, Franclin Costa do; FARIA, Rogério. A Questão da Inclusão na Rede Federal de Educação Profissional, Científica e Tecnológica, a partir da Ação TEC NEP, In: NASCIMENTO, Franclin Costa do; FLORINDO, Girlane Maria Ferreira; SILVA, Neide Samico da. (orgs.). Educação profissional e tecnológica inclusiva: um caminho em construção. Brasília: IFB, 2013. 217p., p. 13 - 23.

NUNES, Sula Cristina Teixeira. O Programa TEC NEP: a educação profissional na perspectiva inclusiva. 2012. Trabalho de Conclusão de Curso (Pós-Graduação em Educação) 
- Faculdade de Educação, Universidade Federal do Rio grande do Sul, Porto Alegre, 2012. Disponível em: <

http://www.lume.ufrgs.br/bitstream/handle/10183/69859/000875096.pdf?sequence=1> Acesso em: 05 nov. 2015.

PEREIRA, Andreia Cabral Colares. As representações docentes sobre os estudantes incluídos nos cursos do IF Sul-Rio-Grandense, campus charqueadas. 2011. Dissertação (Mestrado em Educação) - Pontifícia Universidade Católica do Rio Grande do Sul, Porto Alegre, 2011.

PEREIRA, Andreia Cabral Colares. Transversalidade, inclusão e práticas pedagógicas: possibilidades para operacionalizar políticas e repensar currículos. 2016. Tese (Doutorado em Educação) - Programa de Pós-Graduação em Educação da Pontifícia Universidade Católica do Rio Grande do Sul, Porto Alegre, 2016.

STAINBACK, Susan e STAINBACK, William. Inclusão: um guia para educadores. Trad. Magda França Lopes. Porto Alegre: Artmed, 1999. 451p.

UNESCO. Declaração de Salamanca: Sobre Princípios, Políticas e Práticas na Área das Necessidades Educativas Especiais, Salamanca-Espanha, 1994.

UNESCO. Declaração Mundial sobre Educação para Todos: plano de ação para satisfazer as necessidades básicas de aprendizagem. UNESCO, Jomtien/Tailândia, 1990.

Recebido em março de 2020.

Aprovado em maio de 2020. 